\title{
A comparison of solar radiative flux above clouds from MODIS with BALTIMOS regional climate model simulations
}

\author{
Anja Hünerbein • Juergen Fischer • Philip Lorenz
}

Received: 13 September 2005 / Accepted: 22 December 2009 / Published online: 26 February 2010

(C) The Author(s) 2010. This article is published with open access at Springerlink.com

\begin{abstract}
A comparison study for the solar radiative flux above clouds is presented between the regional climate model system BALTEX integrated model system (BALTIMOS) and Moderate Resolution Imaging Spectroradiometer (MODIS) satellite observations. For MODIS, an algorithm has been developed to retrieve reflected shortwave fluxes over clouds. The study area is the Baltic Sea catchment area during an 11-month period from February to December 2002. The intercomparison focuses on the variations of the daily and seasonal cycle and the spatial distributions. We found good agreement between the observed and the simulated data with a bias of the temporal mean of $13.6 \mathrm{~W} / \mathrm{m}^{2}$ and a bias of the spatial mean of $35.5 \mathrm{~W} / \mathrm{m}^{2}$. For summer months, BALTIMOS overestimates the solar
\end{abstract}

\footnotetext{
A. Hünerbein $(\bowtie) \cdot J$. Fischer

Freie Universität Berlin,

Institut für Weltraumwissenschaften (WeW),

Carl-Heinrich-Becker-Weg 6-10,

12165 Berlin, Germany

e-mail: anja.huenerbein@googlemail.com

P. Lorenz

Max-Planck-Institute for Meteorology,

Bundesstrasse 53,

20146 Hamburg, Germany

Present Address:

A. Hünerbein

Deutscher Wetterdienst /,

Richard-Aßmann-Observatorium (FELGd),

Am Observatorium 12,

15848 Tauche, Germany

Present Address:

P. Lorenz

Freie Universität Berlin, Institut für Meteorologie,

Carl-Heinrich-Becker-Weg 6-10,

12165 Berlin, Germany
}

flux with up to $90 \mathrm{~W} / \mathrm{m}^{2}$ (20\%). This might be explained by the insufficient representation of cirrus clouds in the regional climate model.

\section{Introduction}

Clouds modify the atmospheric radiation fields. They absorb and scatter the incoming solar radiation, while they emit thermal infrared radiation according to their temperature. Clouds play an important role in regulating the energy and water cycle by altering precipitation and the radiation budget. The transfer of radiation through clouds depends on their microphysical and macrophysical properties like stratification, cloud height, particle size and optical thickness.

Correct cloud parameterisation schemes in numerical models are critical for accurate weather forecasting and climate modelling. Various investigations have recognised that the highly parameterised cloud processes and the resulting cloud-climate interactions represent one of the main uncertainties in climate modelling (Cess et al. 1990; Gates 1992; Chen and Roeckner 1996).

In a recent investigation, a comparative study in a Baltic Sea Experiment (BALTEX) has been carried out with eight regional atmospheric model systems and available analyses or observational data. One of the examined regional climate models is the BALTEX integrated model system (BALTIMOS). Jacob et al. (2001) show disagreements between the BALTIMOS model data and observations of the surface radiation and the cloud cover. These results exhibit discrepancies in the prediction of the cloud fields as well as of the radiation effects. Therefore, this study investigates the accuracy of the cloud solar radiation at the top of the atmosphere by comparing the simulated solar radiation flux above clouds with satellite measurements from Moderate Resolution Imaging Spectror- 
adiometer (MODIS). We consider the annual cycle, daily cycle and spatial distribution of the annual mean. Long-term objective is to improve the cloud scheme within the coupled model system BALTIMOS.

To understand variations of the Earth's radiation fluxes and the effect of clouds on the atmospheric radiation fields, several space missions have been dedicated to observe the Earth's radiation budget. Most notable are the Nimbus-7 (Jackobowitz et al. 1984), the Earth Radiation Budget Experiment (ERBE; Barkstrom and Smith 1986), the ScaRab (Kandel et al. 1994) and Clouds and Earth's Radiant Energy System (CERES; Wielicki et al. 1995). The ERBE was one of the most important programmes to study the Earth's radiation fluxes, and it has been used widely for climate studies (Barkstrom et al. 1989; Harrison et al. 1990). Special focus has been emphasised on the role of clouds in changing the Earth's radiation budget (Ramanathan et al. 1989).

To obtain high spatial resolution satellite observations for the intercomparison, MODIS data have been chosen. On board the Terra and Aqua satellites, MODIS (King et al. 1992) provides global coverage of the Earth every 1 to 2 days since 2000. MODIS has 19 spectral bands in the solar spectrum with a spatial resolution of $1 \mathrm{~km}$ in nadir direction. We developed an algorithm to derive the upward shortwave radiation above clouds from MODIS data. Key approach of the algorithm is the conversion of the MODIS narrow band radiance measurements to broadband fluxes to derive the shortwave upward flux above clouds (Hünerbein 2006).

For an 11-month period from February to December 2002, the shortwave upward fluxes above clouds are retrieved from MODIS data to validate the BALTIMOS regional climate model. The intent is to evaluate the representation of the shortwave radiation in a cloudy atmosphere, simulated by the coupled BALTIMOS model system for the Baltic Sea catchment area. To reveal the differences in the modelled and the observed upward solar radiative flux at the top of the atmosphere, daily and annual cycles are analysed.

First, the method to retrieve the shortwave flux from MODIS observation is described, then the regional climate model BALTIMOS is introduced. The results are presented in Section 3 followed by the discussion of the comparison in the last section.

\section{Theory}

\subsection{MODIS satellite observational data}

To obtain reflected shortwave fluxes from the top of the atmosphere, the measured radiance from a narrow-field-ofview scanning radiometer MODIS in a particular sun-earthobserver viewing geometry are converted to broadband fluxes to estimate the top of the atmosphere shortwave flux. To solve the inversion problem of the narrowband reflectance from MODIS to broadband solar upward fluxes, we use a radiative transfer model.

Previous Earth Radiation Budget experiments as, e.g., ERBE or CERES, have been using angular distribution models (ADMs) to take into account the angular dependence of the radiation field (Suttles et al. 1988; Loeb et al. 2003a). Monitoring the change of radiative energy budget at the top of the atmosphere with a higher spatial resolution was the main motivation to choose narrowband observations from MODIS. The spatial resolution is approximately $1 \mathrm{~km}$ at nadir against $20 \mathrm{~km}$ for CERES measurements.

The used radiances from MODIS bands 0.46, 0.55, 0.64, $0.83,0.91,0.93,0.941 .24,1.63$ and $2.12 \mu \mathrm{m}$ have been extracted and converted to reflectance's normalised to solar irradiances.

The algorithm follows two steps:

1. The narrowband-to-broadband conversion for a series of 2,600 cases is performed with radiative transfer calculations for MODIS observation.

Radiative transfer simulations are applied to simulate the complete radiation field in a plan-parallel atmosphere using the matrix operator method (Plass et al. 1973; Fell and Fischer 2001). Gaseous absorption within the solar spectrum is treated using the k-distribution technique for transmission (Goody and Young 1989; Bennartz and Fischer 2000) with the absorption line parameters of the main atmospheric absorbers from the HITRAN dataset (Rothman et al. 2003).

The atmosphere is modelled by homogeneous layers characterised by the single scattering parameters of each scattering component in the atmosphere (molecules, aerosols and cloud particles). The adding-and-doubling model MOMO (Fell and Fischer 2001) is used to calculate the reflectance of 200 individual narrow bands to cover the entire solar spectral domain including the used ten MODIS bands.

The radiances are calculated for a discrete set of solar zenith angles, viewing zenith angles and azimuth differences to build up a dataset. The cases depend on the physical properties of the clouds like stratification, particle radius, cloud height and optical thickness as well as ground reflection, aerosols and water vapour. The radiation flux was calculated for each case.

2. The second step is the inversion to retrieve solar upward flux from actually observed radiance measurements. The aim of the inversion is to generate an operation that relates the MODIS measurements at all considered bands $\left(I_{1}, \ldots, I_{10}\right)$ and the observed geometrical parameters [solar zenith angle $(\theta)$, viewing zenith angle $(\theta)$ and the azimuth difference $(\phi)]$ as well as surface albedo $(s)$ to upward solar flux $(F)$.

$\left(I_{1}, . ., I_{10}, \theta, \phi, s\right) \rightarrow(F)$. 
The inverse model consists of a multilayer perceptron neuronal network. The neuronal network training is based on the simulated dataset. An independently created test dataset is simulated to identify the potential biases in the radiance-toflux conversion. When stratified by solar zenith angles, topof-atmosphere (TOA) fluxes from different angles are consistent within 3\% (e.g. 2\% CERES product, Loeb et al. 2003b). A detailed description of the algorithm can be found in Hünerbein (2006).

The developed algorithm has been validated against the measurements from CERES. The instrument CERES is also on board the Terra platform. TOA radiative fluxes from CERES are estimated from empirical ADMs that convert instantaneous radiance measurements to TOA fluxes, the $\mathrm{TOA} /$ surface fluxes and clouds (SSF) product.

The accuracy of CERES TOA fluxes obtained from the new set of ADMs developed for the CERES instrument have been estimated from Loeb et al. (2003b). Additionally, the CERES data are processed by the ERBE-like product which uses the ERBE scene identification and ADMs to derive TOA fluxes from CERES measurements. The regional instantaneous shortwave top of the atmosphere flux errors in all-sky conditions are given with $24.4 \mathrm{~W} / \mathrm{m}^{2}$

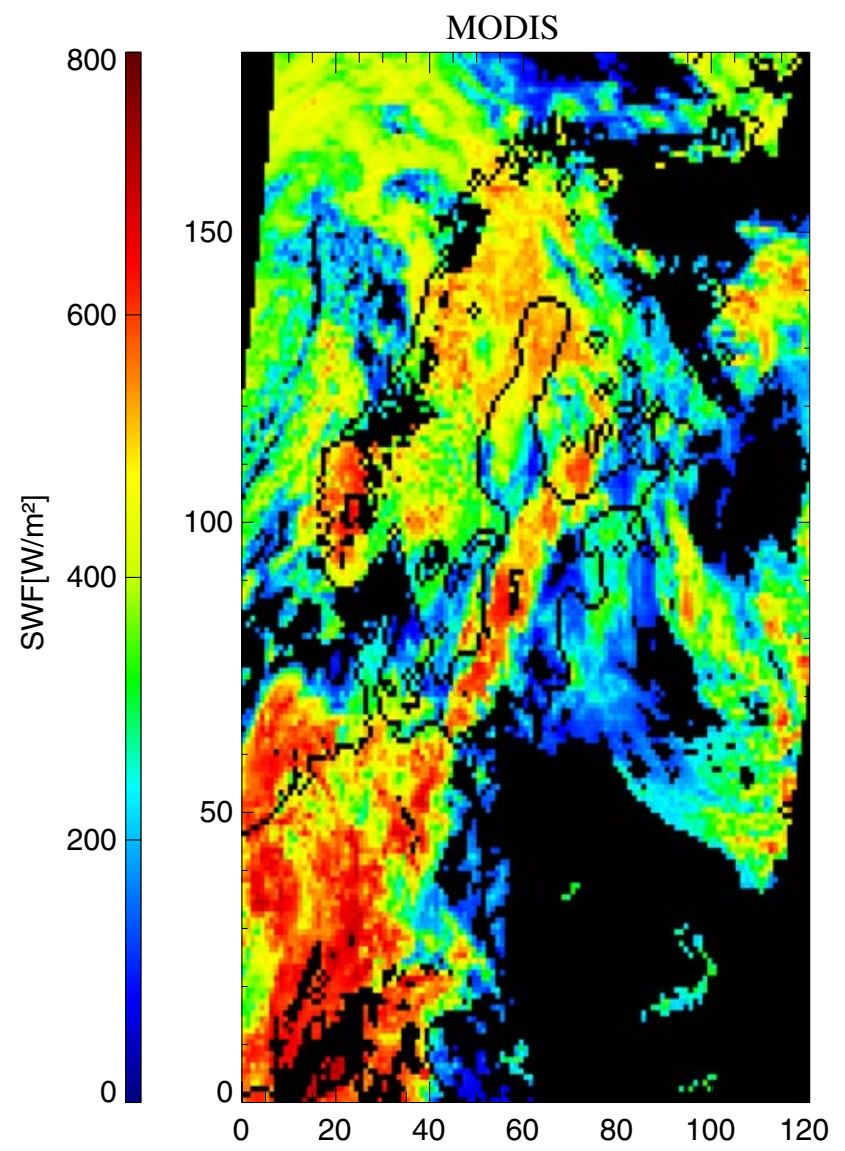

for ERBE-like product and $10.8 \mathrm{~W} / \mathrm{m}^{2}$ for the new SSF product from CERES.

For intercomparison between the MODIS narrowband product and the CERES products, we have chosen 12 overpasses through 1 year. The CERES point spread function is used to convert the MODIS measurements to the spatial resolution from CERES (Smith 1994). The comparison gives a root-mean-square error of $37.9 \mathrm{~W} / \mathrm{m}^{2}$ for the ERBE-like product and $29.7 \mathrm{~W} / \mathrm{m}^{2}$ for the SSF product (Hünerbein 2006).

MODIS observations from Terra in descending note and from Aqua in ascending note are used for the intercomparison. Thus, the BALTIMOS area is covered by MODIS observations at least twice a day between 0800 UTC and 1300 UTC. The clouds are selected applying the MODIS-FUB cloud mask which is developed at the "Freie Universität Berlin".

MODIS observations are transformed to the BALTIMOS common grid of $1 / 6^{\circ} \times 1 / 6^{\circ}$. The interpolation over the observed data is performed by downscaling to the model grid.

A time difference $<30$ min between a MODIS measurement and BALTIMOS is permitted.

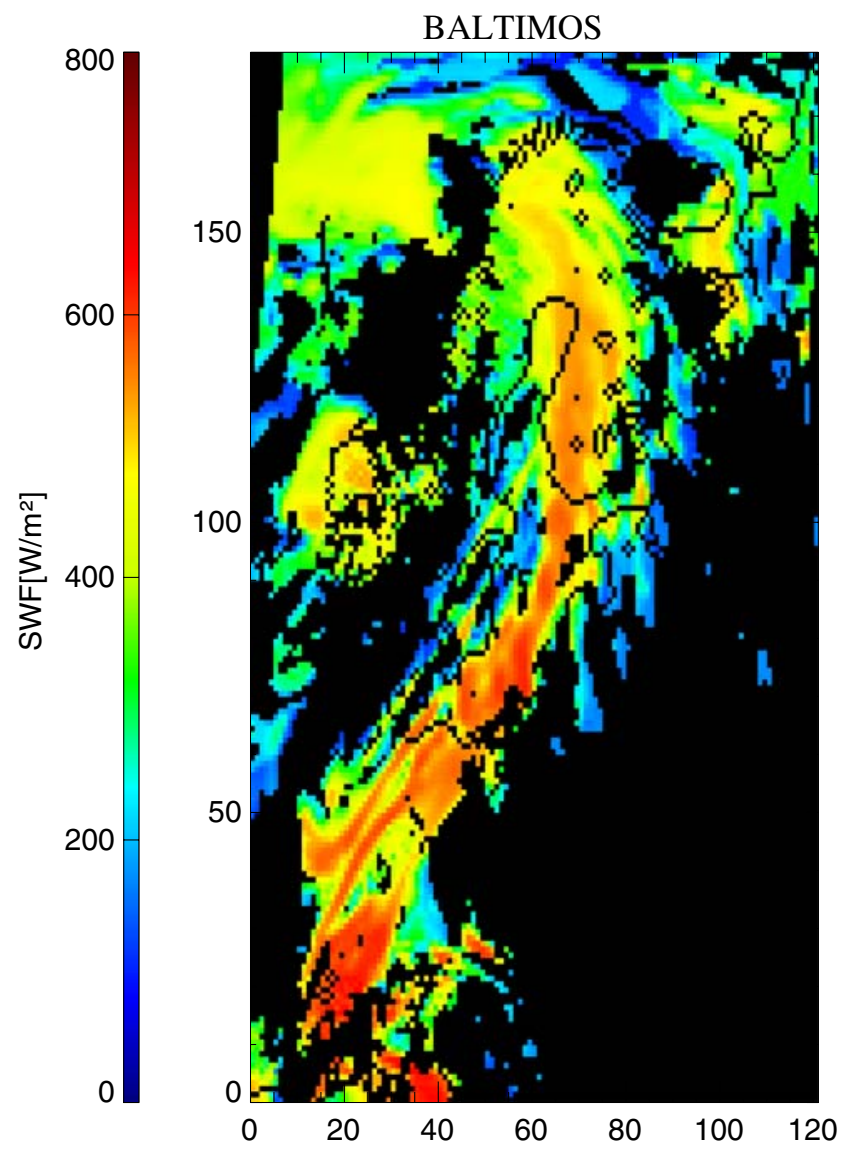

Fig. 1 Shortwave flux $(S W F)$ at the top of the atmosphere $\left(\mathrm{W} / \mathrm{m}^{2}\right)$ : observed (MODIS) (left) and modelled (coupled BALTIMOS) SWF (right) for 2 May 2002 at 1000 UTC 


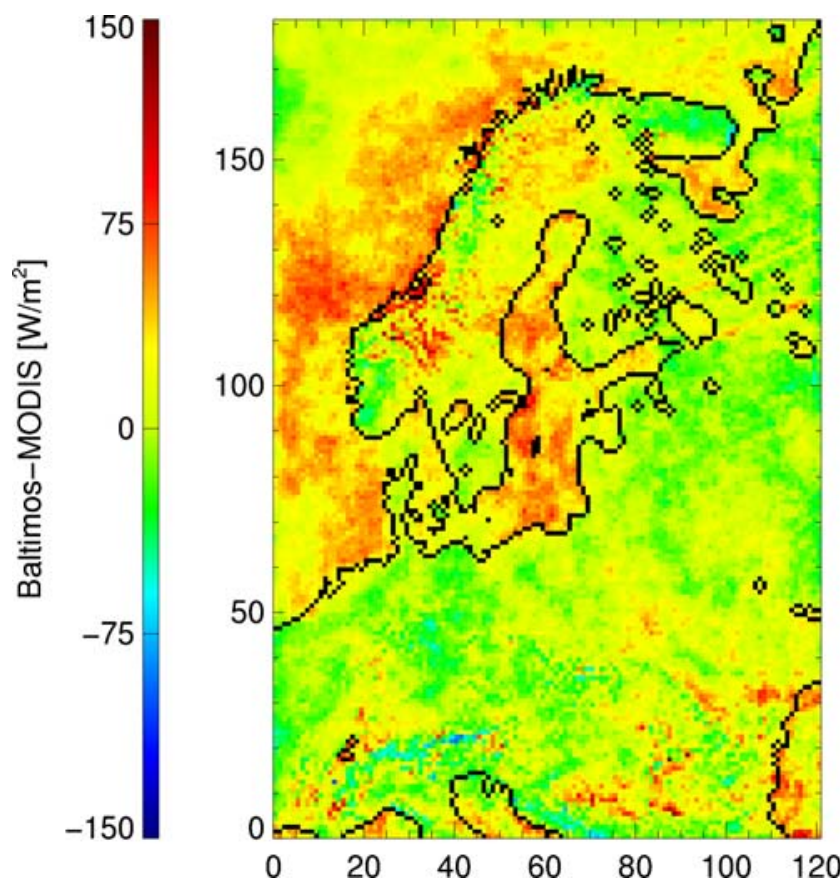

Fig. 2 Spatial distribution of the mean difference (coupled BALTIMOSMODIS, W/m $/ \mathrm{m}^{2}$ ) averaged for the time period February-December 2002 for the observed and modelled shortwave flux at top of the atmosphere in cloudy conditions for the entire BALTIMOS scene

\subsection{The regional climate model BALTIMOS}

A fully integrated model system for the Baltic Sea basin, called BALTIMOS, has been developed by coupling atmospheric model components of REMO (Jacob and Podzun 1997) with the BSIOM components for the ocean and sea ice (Lehmann 1995 ) and the LARSIM model for the hydrology (Richter and Ludwig 2003; Bremicker 2000). A detailed description of the coupled model system BALTIMOS is provided in this issue (Lorenz and Jacob 2010). The horizontal resolution of the model is $1 / 6^{\circ} \times 1 / 6^{\circ}(\sim 18 \mathrm{~km})$ in a rotated grid system. The model domain covers the Baltic Sea and its catchment area (Lorenz and Jacob 2010). Vertically, BALTIMOS has 20 atmosphere levels and 60 ocean levels.

This study focuses on the atmosphere model (REMO) and its radiation scheme. The regional climate model REMO originates from the Europa-Modell (Majewski 1991), which is the former numerical weather prediction model of the German Weather Service. The physical parameterisation scheme in REMO refers to the global climate model ECHAM4 (Roeckner et al. 1996). Furthermore, the radiation scheme is based on the ECMWF scheme (ECMWF Research Department 1991), with minor modifications. For the shortwave radiation, the scheme considers two intervals, one for the visible $(0.2-0.68 \mu \mathrm{m})$ and one for the nearinfrared $(0.68-4.0 \mu \mathrm{m})$ part of the solar spectrum.

For the intercomparison, the time step of the atmosphere model is $120 \mathrm{~s}$, whereby the shortwave flux is being calculated every hour. Between the hourly radiative calculations, these fluxes are constant. The radiative effects of clouds are updated every hour.

The simulations with BALTIMOS are performed with an hourly output of the main variables for February 2002 to December 2002. The models were operated in the climate mode, which means that in the beginning they were initialised and then continuously forced at the lateral boundaries from ECMWF analyses.

To select only cloudy BALTIMOS grid boxes for the intercomparison, the additional information on the modelled cloud cover fraction of BALTIMOS is used. The cloud cover fraction has to be larger than $90 \%$.
Fig. 3 The annual cycle are calculated for the observed and modelled shortwave flux at top of the atmosphere in cloudy conditions for the entire BALTIMOS scene for the time period February-December 2002. The bars are the standard deviation MODIS values (cross), coupled BALTIMOS (triangle), uncoupled BALTIMOS (square): for all clouds (a); without thin clouds (b)
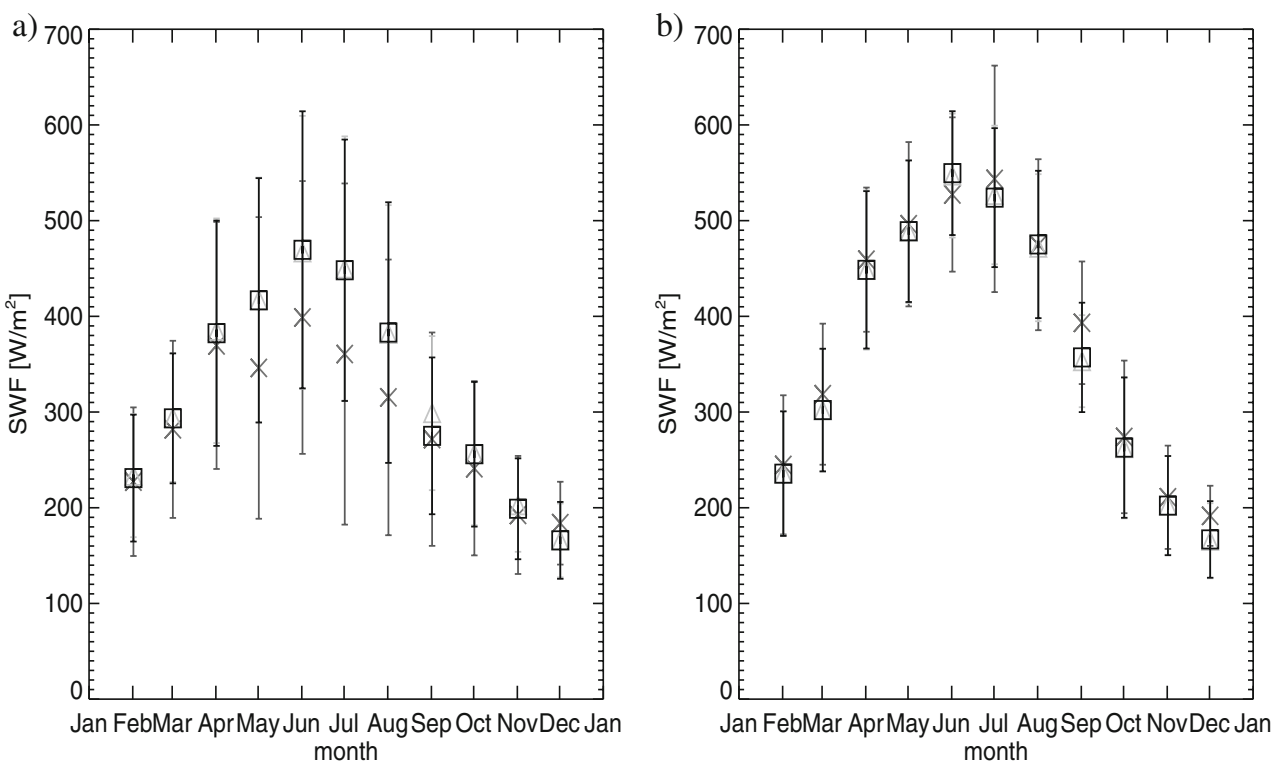


\section{Results}

The estimated solar reflectance and flux by BALTIMOS and MODIS are compared over the BALTEX region for an 11-month period from February to December 2002. The regional climate model has been operated for a coupled and uncoupled system. The uncoupled model BALTIMOS (without an ocean model) has shown similar results as the coupled model BALTIMOS.

We have started with an example without a time or spatial average to illustrate the differences between the simulation and the observation (Fig. 1). A frontal system developed over Europe on 2 May 2002 at 1000 UTC can be recognised from the observation and the simulation. The measured shortwave radiative fluxes from MODIS show more spatial variability, which can be explained by the different temporal resolution as the BALTIMOS shortwave flux is an hourly average and not an instantaneous value.

The general weather situation on May 2 has been dominated by an occluded front passing Europe in a bow from north Scandinavia to the Alps. The low-pressure centre at the surface was located over the northeast Atlantic Ocean. A less significant front remained east of the considered region. Both, the observation and the simulation, show the occluded front which covers northern Europe. The climate simulation catches the frontal system in general, but the distribution and the position are different compared to the observations. The easterly front was not simulated. Following, we will not focus on single cases but on the whole time set to compare the spatial distribution and the annual cycle as well as the diurnal cycle.

Absolute differences are calculated by: BALTIMOS minus MODIS. The spatial distribution of the annual mean difference is in the range of $\pm 150 \mathrm{~W} / \mathrm{m}^{2}$ (Fig. 2). For most parts, the difference is $<50 \mathrm{~W} / \mathrm{m}^{2}$. The largest discrepancies are observed over the Baltic Sea and the Alps. The BALTIMOS gives a higher estimate over the sea and a smaller estimate over the Alps. The MODIS-FUB cloud mask shows problems in the cloud identification over snow-covered regions like in the Alps. When the cloud mask misclassifies the snow-covered regions as clouds, the observation overestimates the shortwave flux.

Remarkable is the systematic differences between results over land and over ocean. Within this study, we could not identify the reason, but we draw up some assumptions. For optical thin clouds $(<10)$, the surface albedo is relevant. The model used for the sea is a mean surface albedo of 0.07 , which could be insufficient. The sea surface albedo is depending on the roughness of the sea surface. For rough sea, the surface albedo can be up to 0.3 (Jin et al. 2004). Another hypothesis would be that the model simulated more dense cloud over the sea than over land due to the evaporation of the sea. This could be explaining the

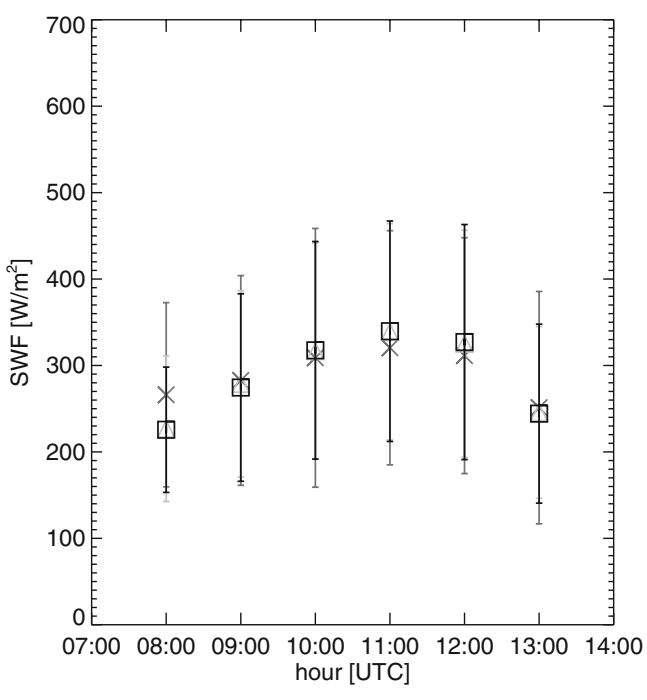

Fig. 4 The daily cycle are calculated for the observed and modelled shortwave flux at top of the atmosphere in cloudy conditions for the entire BALTIMOS scene for the time period February-December 2002. The bars are the standard deviation MODIS values (cross), coupled BALTIMOS (triangle), uncoupled BALTIMOS (square)

generally positive differences over the sea and the negative difference over the land.

The modelled and the observed annual cycle are shown in Fig. 3. In Fig. 3a all cloudy cases and in Fig. 3b only thick clouds are chosen for the comparison. Information over the cloud types was not available for this study. Therefore, we defined a threshold to separate thin clouds, which are associated with cirrus, from all clouds. Dealing with cirrus clouds is always problematic for regional models as well as satellite observations. The albedo of cirrus is estimated up to 0.4 (Jacobson 1999; von Storch et al. 1999). We used this threshold as an additional parameter for the comparison. The curves of the monthly mean reflect the solar insolation. During the months of May, June, July and August, the model overestimates the shortwave upward flux above clouds (Fig. 3a, bias $35.5 \mathrm{~W} / \mathrm{m}^{2}$ ), whereas in Fig. 3b, the regional model and the MODIS shortwave flux are in good agreement (bias $11.04 \mathrm{~W} / \mathrm{m}^{2}$ ).

Table 1 Statistics on top-of-atmosphere shortwave flux

\begin{tabular}{lccc}
\hline & Total distribution $^{\mathrm{a}}$ & Annual cycle $^{\mathrm{b}}$ & Annual cycle $^{\mathrm{c}}$ \\
\hline Bias $\left(\mathrm{W} / \mathrm{m}^{2}\right)$ & 13.6 & 35.5 & 11.04 \\
rmse $\left(\mathrm{W} / \mathrm{m}^{2}\right)$ & 28.5 & 51.7 & 17.9 \\
Correlation & 0.77 & 0.97 & 0.99 \\
\hline
\end{tabular}

${ }^{a}$ Values represent the statistics between the observed and modelled dataset for the temporal mean

${ }^{\mathrm{b}}$ Values represent the statistics between the observed and modelled dataset for the spatial mean for all clouds

${ }^{\mathrm{c}}$ Values represent the statistics between the observed and modelled dataset for the spatial mean without thin clouds 
Figure 4 illustrates the diurnal cycle from 8 to 13 UTC. The maximum is at $12 \mathrm{UTC}$ as expected with the maximum in the solar irradiation. The model corresponds well to the measured data. The error bars indicate the standard deviation. The amplitude and phase of the annual and diurnal variation are consistent.

For a more differentiated interpretation of the biases between modelled and observed shortwave flux, the bias of the temporal mean of each grid box and the bias of the annual cycle are listed in the Table 1 . The differences of the temporal mean show a smaller bias for the total distribution $\left(13.6 \mathrm{~W} / \mathrm{m}^{2}\right)$ than the annual cycle bias $\left(35.5 \mathrm{~W} / \mathrm{m}^{2}\right)$, whilst the correlation of the temporal mean $(0.77)$ is less than the annual cycle correlation (0.97).

\section{Discussion and conclusion}

The upward shortwave flux in the regional climate model BALTIMOS (uncoupled and coupled) is validated with MODIS satellite data applying a new method to estimate the shortwave upward flux above clouds. The comparison has been performed for the entire model domain through a period of almost 1 year.

The major results from the validation are as follows:

The spatial variation over the mean differences between observed and modelled upward flux shows high variations (Fig. 2), but no significant bias. Over the Baltic Sea, the regional climate model overestimates the shortwave radiative flux, and in contrast over the Alps, the model underestimates the shortwave radiative flux. For the temporal distribution, differences in the annual cycle are found and discussed. Discrepancy is found in the summer month. The BALTIMOS shortwave radiative flux is higher. An extraction of the cirrus clouds leads to an improved agreement from $51.7 \mathrm{~W} / \mathrm{m}^{2}$ rmse with cirrus and $17.9 \mathrm{~W} / 2$ rmse without. Generally, between the coupled and uncoupled simulations, no considerable differences are found.

The differences are due to various reasons:

- Snow/ice detection of the cloud mask in the MODIS processing

As previously discussed, the problem of the scene identification for the snow and ice detection leads to an overestimation of the cloud cover. Thus, the upward shortwave radiative flux is overestimated by the satellite observations. The overestimation is recognised in the Alps.

\section{- Different cloud fields}

The regional climate model describes frontal cloud systems well, which are mainly driven by the lateral boundaries. In particular, convective clouds are simulated on different locations and distributions. These discrepancies are expressed in the high variation of the spatial distribution of the compared fluxes.

\section{- Model deficiencies}

The very high cloud reflection values of the regional climate model in the annual cycle (Fig. 3) cause discrepancies in the summer months. The reason for these problems could either be the improper estimation of humidity by dynamics processes or poor simulation of cloud physics processes for cirrus clouds in the regional climate model.

However, a separation in different cloud types would be useful information for future investigations to understand the differences between the observed and simulated cloud radiative forcing.

Acknowledgements The authors are grateful to Daniela Jacobs from the Max-Planck-Institute for Meteorology for her comments and discussions regarding this work. This research was funded by the German BMBF under contract number 01 LD 0027 in the framework of DEKLIM/BALTIMOS. Partial support of this research was also given by grants from the Berlin Programm zur Förderung der Chancengleicheit für Frauen in Forschung und Lehre. Geo-referenced and calibrated top-ofatmosphere radiance measurements stored in Level-1b data are being provided by the NASA Distribution Active Archive Centre (DAAC).

Open Access This article is distributed under the terms of the Creative Commons Attribution Noncommercial License which permits any noncommercial use, distribution, and reproduction in any medium, provided the original author(s) and source are credited.

\section{References}

Barkstrom BR, Smith GL (1986) The earth radiation budget experiment: science and implementation. Rev Geophys 24:379-390

Barkstrom BR et al (1989) Earth Radiation Budget Experiment (ERBE) archival and April 185 results. Bull Amer Meteor Soc 70:1254-1262

Bennartz R, Fischer J (2000) A modified k-distribution approach applied to narrow band water vapour and oxygen absorption estimates in the near infrared. J Quant Spectosc Radiat Transfer 66:539-553

Bremicker, M. (2000) Das Wasserhaushaltsmodell LARISMModellgrundlagen und Anwendungsbeispiele, Freiburger Schriften zur Hydrologie, Band 11

Cess RD et al (1990) Intercomparison and interpretation of climate feedback processes in 19 atmospheric general circulation models. J Geophys Res 95:16601-16615

Chen C-T, Roeckner E (1996) Validation of the earth radiation budget as simulated by the Max Planck Institute for Meteorology general circulation model ECHAM4 using satellite observations of the Earth Radiation Budget Experiment. J Geophys Res 101:42694287

ECMWF Research Department (1991) ECMWF forecast model, physical parameterization. Research manual 3, 3rd edn. Meteorological Bulletin, European Centre for Medium Range Weather Forecasts, Reading, England

Fell F, Fischer J (2001) Numerical simulation if the light field in the atmosphere-ocean system using the matrix-operator method. J Qaunt Spectoscop Radiat Transfer 69:351-388

Gates WL (1992) AMIP: the atmospheric model intercomparison project. Bull Am Meteorol Soc 73:1962-1970 
Goody RM, Young YL (1989) Atmospheric radiation (theoretical basis). Oxford University Press, Oxford, p 519

Harrison EF, Minnis P, Barkstrom BR, Ramanathan V, Cess RD, Gibson GG (1990) Seasonal variation of cloud radiative forcing derived from Earth Radiation Budget Experiment. J Geophys Res 95:18,687-18,703

Hünerbein A (2006) Fernerkundung des solaren aufwärtsgerichteten Strahlungsflusses über Wolken mit räumlich hochaufgelösten Satellitenmessunge. Doctor thesis, Frei Universität Berlin. Available online at: www.diss.fu-berlin.de/2007/94

Jackobowitz H, Soule V, Kyle HL, House FB, the ERB Nimbus- 7 Experiment Team (1984) The Earth Radiation Budget (ERB) experiment: an overview. J Geophys Res 89:5021-5038

Jacob D, Podzun R (1997) Sensitivity studies with the regional climate model REMO. Meteorol Atmos Phys 63:119-129

Jacob D, Van den Hurk BJJM, Andrae U, Elgered G, Fortelius C, Graham LP, Jackson SD, Karstens U, Köpken C, Lindau R, Podzun R, Rockel B, Rubel F, Sass BH, Smith RNB, Yang X (2001) A comprehensive model intercomparison study investigating the water budget during the BALTEX-PIDCAP period. Meteorol Atmos Phys 77:19-43

Jacobson MZ (1999) Fundamentals of atmospheric modeling. Cambridge University Press, Cambridge, p 656

Jin Z, Charlock TP, Smith WL Jr, Rutledge K (2004) A parameterization of ocean surface albedo. Geophys Res Lett 31:1-4

Kandel RS, Monge J-L, Viollier M Pakhomov, LA AVI, Reitenbach RG, Raschke E, Stuhlmann R (1994) The ScaRaB project: earth radiation budget observationns from meteor satellites. Adv Space Res 14:47-57

King MD, Kaufman YJ, Menzel WP, Tanré D (1992) Remote sensing of cloud, aerosol, and water vapour properties from the Moderate Resolution Imaging Spectrometer (MODIS). IEEE Trans Geosci Remote Sens 30:1-27

Lehmann A (1995) A three-dimensional baroclinic eddy-resolving model of the Baltic Sea. Tellus 47A:1013-1031

Loeb NG, Manalo-Smith N, Kato S, Miller WF, Gupta SK, Minnis P, Wielicki BA (2003a) Angular distribution models for top-ofatmosphere radiative flux estimation from the Clouds and the Earth's Radiant Energy System instrument on the tropical rainfall measuring mission satellite part I. Methodol J Applied Meteorology 42:240-265
Loeb NG, Manalo-Smith N, Kato S, Miller WF, Gupta SK, Minnis P, Wielicki BA (2003b) Angular distribution models for top-ofatmosphere radiative flux estimation from the Clouds and the Earth's Radiant Energy System instrument on the tropical rainfall measuring mission satellite part II. Valid J Applied Meteorology 42:1748-1769

Lorenz P, Jacob D (2010) BALTIMOS - a fully coupled modelling system for the Baltic Sea and its drainage basin. Theor Appl Climatol. doi:10.1007/s00704-009-0178-x

Majewski D (1991) The Europa-Modell of the Deutscher Wetterdienst ECMWF. Seminar on Numerical Methods in Atmospheric Models 2:147-191

Plass GN, Kattawar GW, Catchings FE (1973) Matrix operator theory of radiative transfer 1: Rayleigh scattering. Appl Opt 12:14-329

Ramanathan V, Cess RD, Harrison EF, Minnis P, Barkstrom BR, Ahmad E, Hartmann D (1989) Cloud-radiative forcing and climate: insights from the earth radiation budget experiment. Science 243:57-63

Richter, K-G, Ludwig K (2003) Analysis of the water cycle of the Baltic Area under present and future conditions. Germane Climate Researche Program (2001-2006), DEKLIM Status Seminar 2003, Bad Münstereifel, 6-8 October 2003, pp 205206

Roeckner E, K Arpe, L Bengtsson, M Christoph, M Claussen, L Dümenli, M Esch, M Giorgetta, U Schlese, U Schulzweida (1996) The atmospheric general circulation model ECHAM-4: model description and simulation of present-day climate Max Planck Institute für Meterologie, Report no. 218

Rothman LS et al (2003) The HITRAN molecular spectroscopic database: edition of the 2000 including updates through 2001. J Quant Spectrosc Radiat Transfer 82:5-44

Smith GL (1994) Effects of time response on the point spread function of a scanning radiometer. Appl Opt 33:7301-7037

Suttles JT et al (1988) Angular radiation models for earth-atmosphere systems, vol I. Shortwave radiation NASA Rep RP-1184. NASA, Washington, p 144

von Storch H, Güss S, Heimann M (1999) Das Klimasystem und seine Modellierung. Springer, Berlin, p 255

Wielicki BA, Barkstrom B, Harrison EF, Lee RB III, Smith GL, Cooper JE (1995) Clouds and the Earth's Radiant Energy System (CERES) an earth observing system experiment. Bull Amer Meteor Soc 76:853-868 